\title{
Indeterminate Pediatric Thyroid Fine Needle Aspirations: A Study of 68 Cases
}

\author{
Matthew Smith ${ }^{a}$ Liron Pantanowitz ${ }^{\mathrm{a}, \mathrm{b}}$ Walid E. Khalbuss ${ }^{\mathrm{a}}$ \\ Vanessa A. Benkovich ${ }^{a}$ Sara E. Monaco ${ }^{a, b}$ \\ a University of Pittsburgh Medical Center (UPMC), and ${ }^{b}$ Children's Hospital of Pittsburgh of UPMC, \\ Pittsburgh, Pa., USA
}

\section{Key Words}

Bethesda · Cytopathology · Fine needle aspiration ·

Indeterminate thyroid nodules · Pediatric thyroid $\cdot$ Thyroid nodules

\begin{abstract}
Objective: The Bethesda System for Reporting Thyroid Cytopathology (TBSRTC) provides a reporting scheme for thyroid fine needle aspiration (FNA) and includes three indeterminate categories with different management strategies. This study analyzes indeterminate thyroid FNAs in children, and correlates these findings with the histological features. Methods: A total of 179 thyroid FNA specimens were retrieved from children. Cases were categorized by TBSRTC. Only cases diagnosed as atypia (AUS)/follicular lesion of undetermined significance (FLUS), suspicious for follicular or oncocytic neoplasm (SFON), or suspicious for malignancy (SM) were selected and correlated with the nodule size and histological follow-up. Results: Sixty-eight cases were identified, including 43 (63\%) AUS/FLUS diagnoses, 19 (28\%) SFON, and 6 (9\%) SM. On follow-up, 48\% were malignant, including 28\% AUS/FLUS cases, 58\% SFON, and 100\% SM. The average size of the malignant lesions diagnosed preoperatively as AUS/FLUS was $1.5 \mathrm{~cm}$ (range 0.7-4.5), compared to $3.3 \mathrm{~cm}$ (range 1.2-6.6) in SFON and $2.8 \mathrm{~cm}$ (range $0.7-3.8$ )
\end{abstract}

in SM. Malignancies included $92 \%$ papillary thyroid carcinoma (PTC), 77\% of which were the follicular variant of PTC (FVPTC) and $8 \%$ follicular carcinomas. The AUS/FLUS cases were largely due to compromised specimens (49\%) and the highest malignancy rate occurred in those with cytological atypia (50\%). Conclusions: This study shows an incremental risk of malignancy within the indeterminate categories using TBSRTC in children. Malignant nodules with a preoperative AUS/FLUS diagnosis tended to be smaller than those with a SFON or SM diagnosis, and the vast majority of malignancies were PTC, with a high proportion being FVPTC.

Copyright $\odot 2013$ S. Karger AG, Basel

\section{Introduction}

Thyroid nodules are uncommon in children; however, they are more frequently malignant than in adults, with an incidence ranging from 9.2 to $28 \%$ [1-3]. Accurate classification is therefore paramount to ensuring appropriate therapy. The Bethesda System for Reporting Thyroid Cytopathology (TBSRTC) is a six-tier system that

Presented in part at the 2012 Annual Meeting of the American Society of Cytopathology in Las Vegas, Nev., USA.

\section{KARGER}

E-Mail karger@karger.com www.karger.com/acy
(C) 2013 S. Karger AG, Basel

0001-5547/13/0574-0341\$38.00/0
Correspondence to: Dr. Sara E. Monaco

UPMC Shadyside Hospital

5150 Centre Avenue, Suite 201, POB2

Pittsburgh, PA 15232 (USA)

E-Mail monacose@upmc.edu 
provides a uniform reporting scheme for thyroid fine needle aspiration (FNA) cytology $[4,5]$. However, most of the data in the recent literature applying TBSRTC are based on populations that are largely comprised of adult patients.

Within the Bethesda system, three categories fall into the indeterminate spectrum: atypia of undetermined significance (AUS)/follicular lesion of undetermined significance (FLUS), suspicious for follicular or oncocytic neoplasm (SFON), and suspicious for malignancy (SM). Cases falling into indeterminate categories were problematic in the past, due to the variety of categories and terminology used in different institutions and the various ways they were managed clinically. However, TBSRTC has helped standardize reporting and management given the incremental risk of malignancy and proposed treatment guidelines $[6,7]$. Recent publications have investigated the indeterminate categories in TBSRTC looking at follow-up data and have shown a malignancy rate that ranges from 5 to $100 \%$, with higher rates of malignancy in the SFON and SM groups than in the AUS/FLUS group [812]. However, in children, the outcomes and clinical correlations in these indeterminate thyroid FNAs classified by TBSRTC have received less attention. Based on a prior study from our institution, thyroid FNAs in the pediatric age group result in approximately $50 \%$ of cases in a definitive diagnosis, including $46 \%$ negative for malignant cells and $4 \%$ positive for malignant cells, and of the surgically excised nodules, $35 \%$ were malignant [13]. In general, the rate of malignancy in surgically excised pediatric thyroid nodules is higher than in adults and has been reported to be up to $49 \%[14,15]$. Given the rate of malignancy in this age group, the goal of this study was to analyze indeterminate thyroid FNAs in a pediatric population and to correlate these findings with clinical and histological features.

\section{Materials and Methods}

During a period of 4.5 years from January 2007 to July 2011, a total of 179 cases of thyroid FNAs in children (aged 21 or younger) were retrieved from the pathology files at the University of Pittsburgh Medical Center. The cytopathologic diagnoses, available clinical information, and histological follow-up were retrospectively reviewed. This study was reviewed and approved by the Institutional Review Board at the University of Pittsburgh Medical Center.

The FNAs were primarily performed under ultrasound guidance $(175$ cases, $98 \%)$ by a radiologist or endocrinologist, while only 4 were performed by pathologists using palpation (4 cases, $2 \%)$. The vast majority of cases had on-site evaluation by a cyto- technologist and/or pathologist, with the exception of cases received in consultation with unavailable intraprocedural information. A 25- to 27-gauge needle was used, and approximately 3-5 passes were performed for each targeted site, depending on adequate material acquisition and tolerability of the procedure. Aspirated material was used for smear preparation, including air-dried slides stained with Diff-Quik and alcohol-fixed slides stained with the Papanicolaou stain. Residual material was submitted for ThinPrep processing, flow cytometry and/or cell block preparation, depending on the immediate interpretation. In addition, material was acquired for potential molecular studies, as described previously [13]. Diagnoses were made by pathologists specializing in cytopathology and/or pediatric pathology.

On retrospective review, cases were categorized based on the diagnostic categories from TBSRTC, and cases were selected if they were diagnosed in any of the three indeterminate TBSRTC categories, including AUS/FLUS, SFON, and SM. The findings were then correlated with histological follow-up and clinicopathologic features.

Cases in the AUS/FLUS category were then subcategorized with qualifiers based on the reason for categorizing a case in this category. These qualifiers included: AUS/FLUS due to a compromised specimen, AUS/FLUS due to cytological atypia, and AUS/ FLUS due to architectural atypia. The AUS/FLUS cases due to a compromised specimen were primarily due to low cellularity or obscuring factors (such as blood or poor fixation). The AUS/FLUS cases attributed to architectural atypia included cases with focal microfollicle formation without cytological features of papillary thyroid carcinoma (PTC), and overall had features falling short of a SFON diagnosis. The AUS/FLUS cases with cytological atypia had focal nuclear atypia, including grooves, peripherally placed nucleoli, or chromatin clearing, that fell short of a SM diagnosis. The histological findings were then correlated in each of these subcategories to see if there were differences in outcome.

\section{Results}

A total of 68 (38\%) indeterminate cases were identified from the 179 pediatric thyroid FNA cases, with a mean age of 17.2 years (range $4-20$ ). Forty-three (63\%) of the indeterminate cases had a diagnosis of AUS/FLUS, 19 (28\%) had a diagnosis of SFON, and 6 (9\%) had a diagnosis of SM. The average age of the AUS/FLUS cases was 17.6 years, 16.0 years for SFON, and 18.0 years for SM.

Histological follow-up was available in $50(73.5 \%)$ of the 68 cases, and included 26 (52\%) benign cases and 24 (48\%) with a malignancy on follow-up. Malignancies included 22 (92\%) cases of PTC, of which 17 (77\%) were a follicular variant of PTC (FVPTC), and 2 (8\%) cases of follicular carcinoma. The cytological and histological results are summarized in table 1 . All of the SM cases were found to be malignant on histological follow-up, and were PTC, and 3 (50\%) of the 6 cases were FVPTC. Representative images of the $\mathrm{SM}$ cases are demonstrated in 

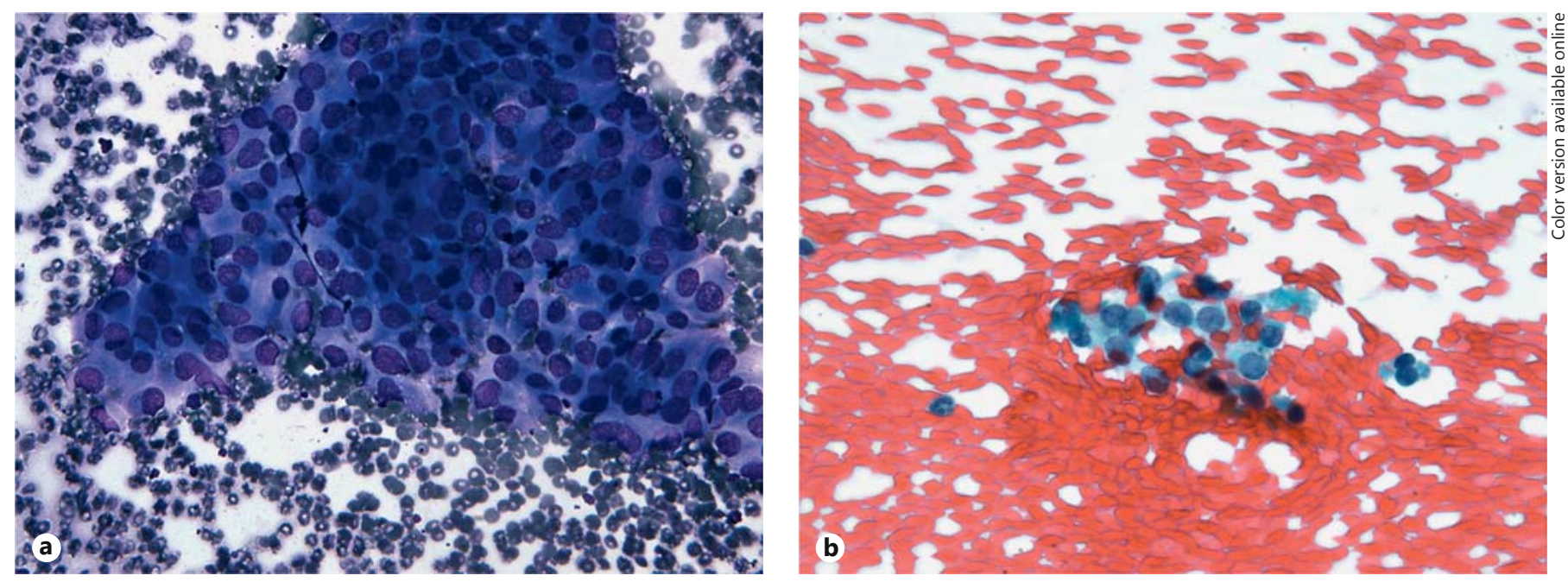

Fig. 1. Pediatric thyroid FNA of SM cases and histological followup. a, b The FNA showed follicular cells with crowding and occasional grooves in large sheets with some oncocytic features, which were suspicious for PTC. a Diff-Quik stain, original magnification $\times 400$. b Papanicolaou stain, original magnification $\times 400$. c The follow-up histology showed a conventional PTC. H\&E, original magnification $\times 400$.

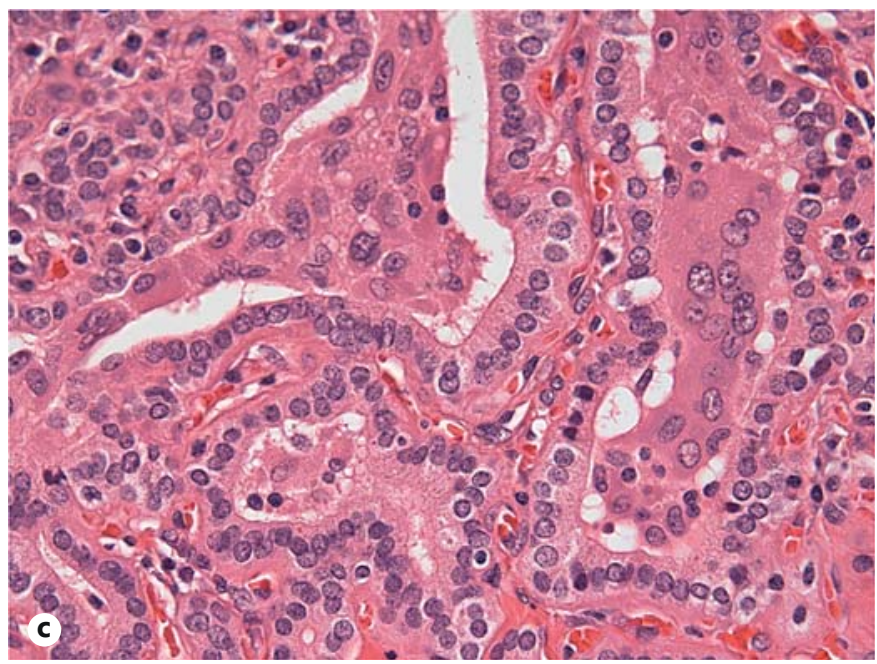

Table 1. Cytological and histological results in indeterminate pediatric thyroid FNAs

\begin{tabular}{|c|c|c|c|c|}
\hline TBSRTC & Overall & Histological & \multicolumn{2}{|c|}{ Final histological diagnosis, n (\%) } \\
\hline AUS/FLUS & $43(63)$ & $25(58)$ & $\begin{array}{l}\text { benign: } 18(72) \\
\text { malignant: } 7(28)\end{array}$ & $\begin{array}{l}13 \text { benign/hyperplasia; } 5 \text { adenomas } \\
6 \text { PTC ( } 4 \text { FVPTC); } 1 \text { follicular carcinoma }\end{array}$ \\
\hline SFON & $19(28)$ & $19(100)$ & $\begin{array}{l}\text { benign: } 8(42) \\
\text { malignant: } 11(58)\end{array}$ & $\begin{array}{l}4 \text { benign/hyperplasia; } 3 \text { adenomas; } 1 \text { granular cell tumor } \\
10 \text { PTC (all FVPTC); } 1 \text { follicular carcinoma }\end{array}$ \\
\hline SM & $6(9)$ & $6(100)$ & $\begin{array}{l}\text { benign: } 0(0) \\
\text { malignant: } 6(100)\end{array}$ & $\begin{array}{l}0 \\
6 \text { PTC (3 FVPTC) }\end{array}$ \\
\hline Total & 68 & $50(73.5)$ & $\begin{array}{l}\text { benign: } 26(52) \\
\text { malignant: } 24(48)\end{array}$ & $\begin{array}{l}17 \text { benign/hyperplasia; } 8 \text { adenomas; } 1 \text { granular cell tumor } \\
22 \text { PTC ( } 17 \text { FVPTC); } 2 \text { follicular carcinomas }\end{array}$ \\
\hline
\end{tabular}

The percentages in column 3 represent the percent of cases in that diagnostic category with histological follow-up, and the percentages in column 4 represent the outcome within the cases with histological follow-up. 


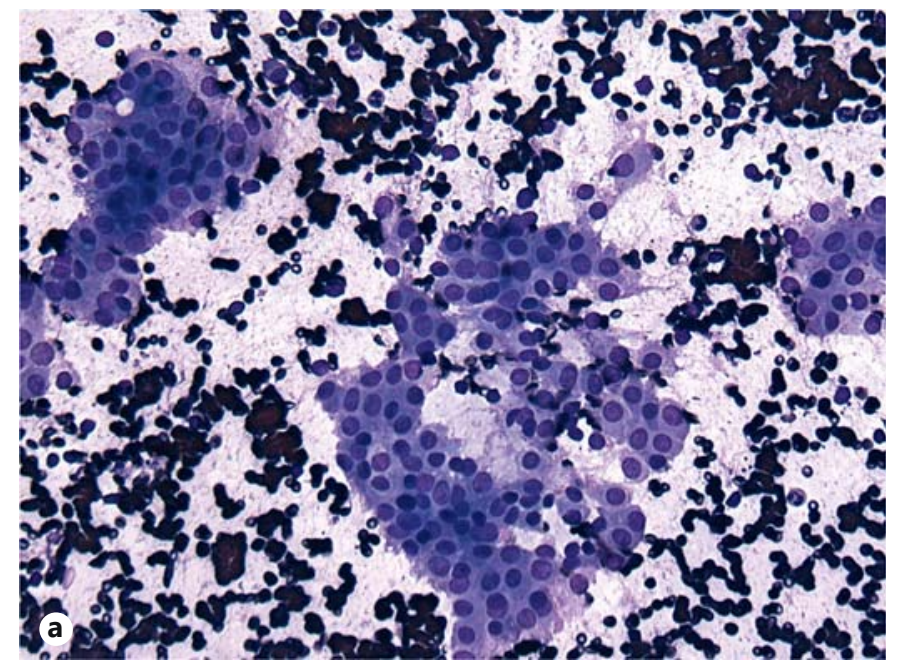

Fig. 2. Pediatric thyroid FNA with SFON diagnosis and histological follow-up. a, b The FNA showed follicular cells in small clusters and microfollicles without definitive nuclear features of PTC. a Diff-Quik stain, original magnification $\times 200$. b ThinPrep, Papanicolaou stain, original magnification $\times 400$. c The follow-up histology showed FVPTC. H\&E, original magnification $\times 400$.

figure 1. Eleven (58\%) of the 19 SFON cases had malignancy on follow-up: 10 PTC (all of them FVPTC) and 1 follicular carcinoma. Of the SFON diagnoses, 13 were suspicious for a follicular neoplasm and 6 were suspicious for an oncocytic neoplasm. On follow-up, 10 of the suspicious for follicular neoplasm cases were malignant ( 9 FVPTC and 1 follicular carcinoma) and 1 of the suspicious for oncocytic neoplasm cases was malignant (1 oncofollicular variant of PTC). Representative images of SFON cases are demonstrated in figure 2 . Seven (16\%) of the 43 AUS/FLUS cases had a malignant histological diagnosis: 6 PTC (4 FVPTC) and 1 follicular carcinoma. Representative images of the AUS/FLUS cases are demonstrated in figure 3.

On subcategorization of the AUS/FLUS cases, the majority of cases were attributed to a compromised speci-
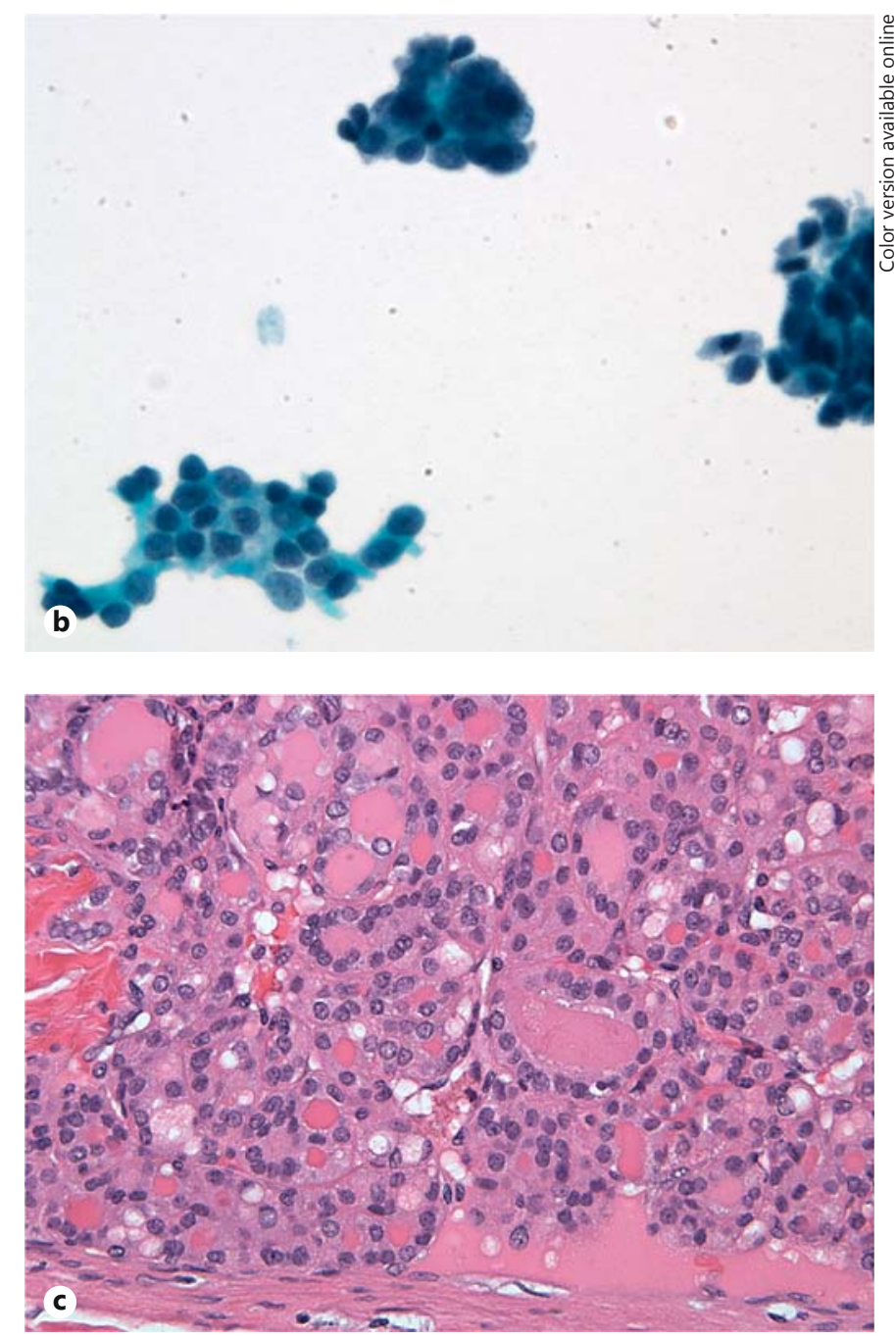

men (21 cases, 49\%), with less attributed to focal cytological atypia (17 cases, $39.5 \%$ ) or focal architectural atypia (5 cases, 11.5\%). On histological follow-up, the compromised AUS/FLUS cases were benign in $83 \%$ cases and malignant in $17 \%$ cases. Of the cases with focal architectural atypia, $80 \%$ were benign on follow-up and $20 \%$ were malignant. The follow-up in cases with focal cytological atypia revealed benign nodules in $50 \%$ of cases and malignant nodules in the other $50 \%$, and all of the malignancies were FVPTC. These findings are summarized in table 2.

The average size of the malignant lesions diagnosed preoperatively as AUS/FLUS was $1.5 \mathrm{~cm}$ (range $0.7-4.5$ ), compared to $3.3 \mathrm{~cm}$ (range 1.2-6.6) in SFON and $2.8 \mathrm{~cm}$ (range 0.7-3.8) in SM, as summarized in table 3. Overall, the malignancies were predominantly (92\%) PTC, $77 \%$ of 

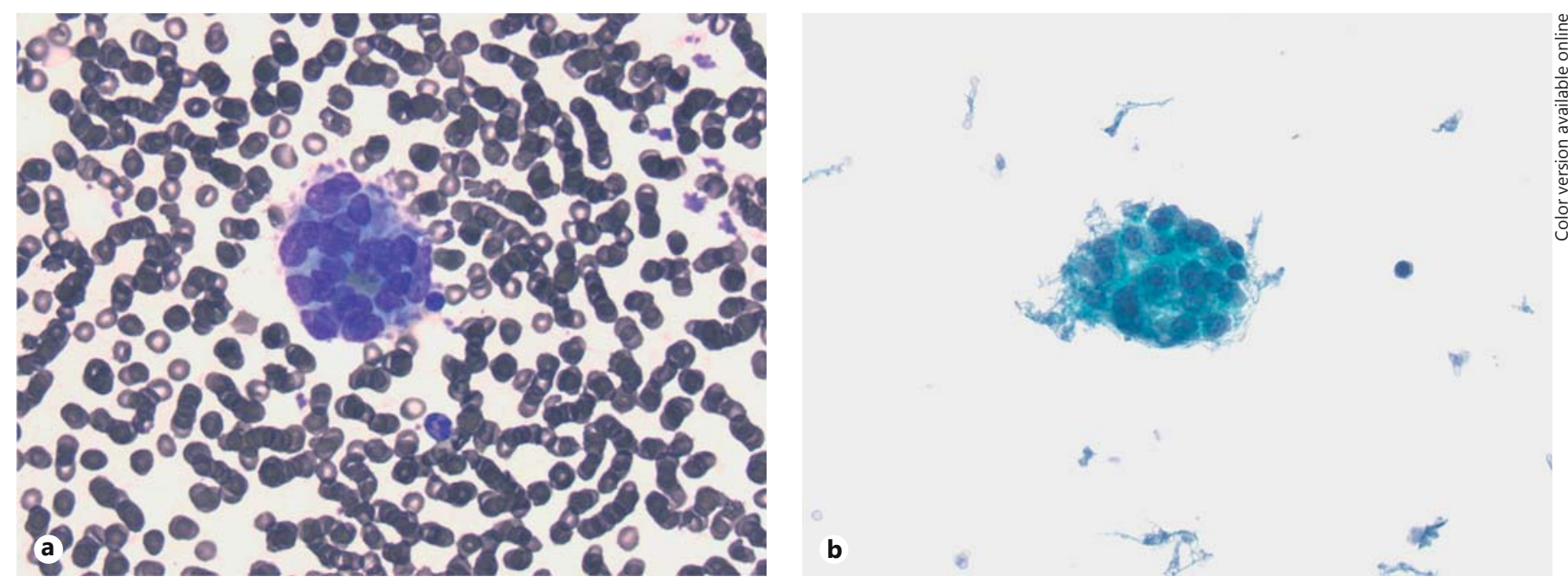

Fig. 3. Pediatric thyroid FNA with AUS/FLUS diagnosis and histological follow-up. a, b The FNA showed a few follicular cells with cytological atypia diluted in blood. a Diff-Quik stain, original magnification $\times 400$. b ThinPrep, Papanicolaou stain, original magnification $\times 400$. c The follow-up histology showed FVPTC. H\&E, original magnification $\times 400$.

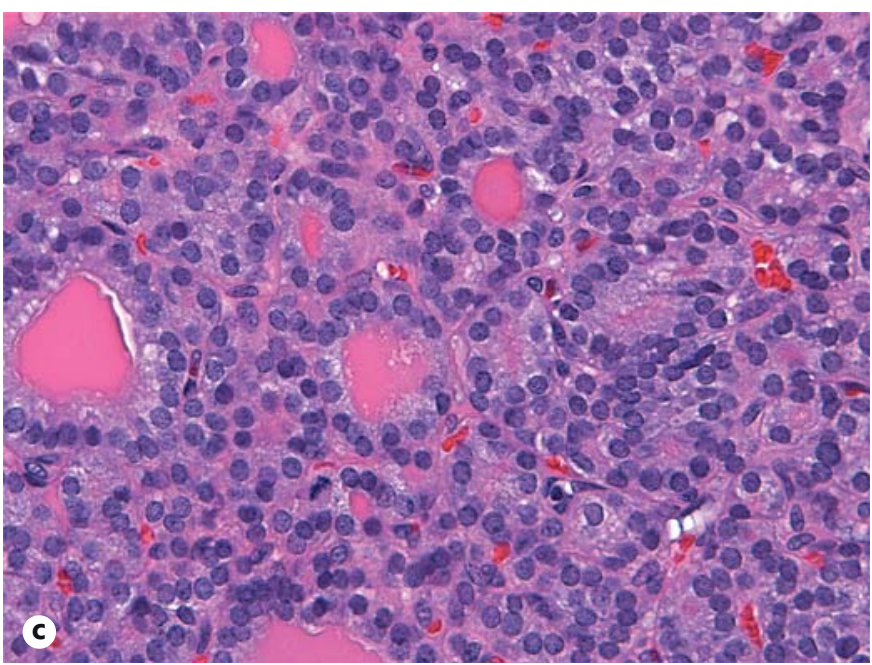

Table 2. Correlation of AUS/FLUS diagnoses in pediatric thyroid FNAs with qualifiers and histological follow-up

\begin{tabular}{|c|c|c|c|c|}
\hline $\begin{array}{l}\text { AUS/FLUS } \\
\text { category }\end{array}$ & $\begin{array}{l}\text { Total cases } \\
\mathrm{n}(\%)\end{array}$ & $\begin{array}{l}\text { Histological } \\
\text { follow-up, n (\%) }\end{array}$ & \multicolumn{2}{|c|}{ Final histological diagnosis, n (\%) } \\
\hline $\begin{array}{l}\text { AUS/FLUS due to } \\
\text { compromised specimen }\end{array}$ & $21(49)$ & $12(57)$ & $\begin{array}{l}\text { benign: } 10(83) \\
\text { malignant: } 2(17)\end{array}$ & $\begin{array}{l}6 \text { benign/hyperplasia; } 4 \text { adenomas } \\
2 \text { PTC ( } 1 \text { FVPTC) }\end{array}$ \\
\hline $\begin{array}{l}\text { AUS/FLUS with } \\
\text { cytological atypia }\end{array}$ & $17(39.5)$ & $8(47)$ & $\begin{array}{l}\text { benign: } 4(50) \\
\text { malignant: } 4(50)\end{array}$ & $\begin{array}{l}2 \text { benign/hyperplasia; } 1 \text { adenoma; } \\
1 \text { lymphocytic thyroiditis } \\
4 \text { PTC ( } 3 \text { FVPTC) }\end{array}$ \\
\hline $\begin{array}{l}\text { AUS/FLUS with } \\
\text { architectural atypia }\end{array}$ & $5(11.5)$ & $5(100)$ & $\begin{array}{l}\text { benign: } 4(80) \\
\text { malignant: } 1(20)\end{array}$ & $\begin{array}{l}4 \text { benign/hyperplasia } \\
1 \text { follicular carcinoma }\end{array}$ \\
\hline Total & 43 & $25(58)$ & $\begin{array}{l}\text { benign: } 18(72) \\
\text { malignant: } 7(28)\end{array}$ & $\begin{array}{l}12 \text { benign/hyperplasia; } 5 \text { adenomas; } \\
1 \text { lymphocytic thyroiditis } \\
6 \text { PTC ( } 4 \text { FVPTC); } 1 \text { follicular carcinoma }\end{array}$ \\
\hline
\end{tabular}

The percentages in column 3 represent the percent of cases in that diagnostic category with histological follow-up, and the percentages in column 4 represent the outcome within the cases with histological follow-up. 
Table 3. Correlation of nodule size and histological results in indeterminate pediatric thyroid FNAs

\begin{tabular}{|c|c|c|c|c|}
\hline \multirow{2}{*}{$\begin{array}{l}\text { TBSRTC } \\
\text { diagnosis }\end{array}$} & \multirow{2}{*}{$\begin{array}{l}\text { Overall } \\
\mathrm{n}(\%)\end{array}$} & \multirow{2}{*}{$\begin{array}{l}\text { Average } \\
\text { age, years }\end{array}$} & \multicolumn{2}{|c|}{ Nodule size, $\mathrm{cm}$} \\
\hline & & & average & range \\
\hline AUS/FLUS & $43(63)$ & 17.6 & 1.5 & $0.7-4.5$ \\
\hline SFON & $19(28)$ & 16.0 & 3.3 & $1.2-6.6$ \\
\hline SM & $6(9)$ & 18.0 & 2.8 & $0.7-3.8$ \\
\hline
\end{tabular}

which were FVPTC, and the remaining 2 cases (8\%) were follicular carcinomas. Benign lesions comprised 52\% of the follow-up diagnoses and were primarily identified in the AUS/FLUS category (18 cases).

\section{Conclusion}

Although thyroid nodules are less common in children when compared to adults, they tend to have a higher rate of malignancy $[1-3,13]$. Indeterminate thyroid nodules are a heterogeneous group of nodules that do not otherwise fit into benign or malignant categories, have a variable incidence of malignancy on follow-up, and have a variety of treatment options. Some recent articles have focused on indeterminate thyroid nodules as outlined by TBSRTC in populations largely comprised of adult patients [8-12]. Our study illustrates that there is an incremental risk of malignancy within the indeterminate diagnostic categories when TBSRTC is applied to a pediatric population, and that the AUS/FLUS cases with focal cytological atypia have a higher risk of malignancy than AUS/FLUS cases due to other factors.

In TBSRTC, the estimated malignancy rate for the AUS/FLUS category is approximately 5-19\%, and increases to $25-45 \%$ for the SFON category and $50-75 \%$ for the SFM category $[4,5]$. In this pediatric population, the malignancy rate was higher for all categories, ranging from $28 \%$ in the AUS/FLUS category to $58 \%$ in the SFON category and $100 \%$ in the SM, with an overall malignancy rate for all indeterminate categories of $48 \%$. Given that this only includes cases with histological follow-up, the rate of malignancy is likely an overestimate, particularly in the AUS/FLUS category. In the publications focusing on the indeterminate category in adult populations, the studies with a higher percentage of cases in the AUS/FLUS category usually have a lower rate of malignancy; however, our study shows that in pediatric thyroid nodules, there may be a larger percentage of cases with atypia falling short of a more definitive category and the corresponding rate of malignancy in these cases may be higher than that seen in adults $[8,13]$. In the studies from our institution looking at predominantly adult patients, the percentage of AUS/FLUS cases was lower (20.5\%), the percentage of cases in the AUS/FLUS category with follow-up was lower $(26 \%)$, and the rate of malignancy in this group was also lower (17\%) [16]. The higher indeterminate rate in this pediatric cohort may be partly due to the fact that the majority of malignancies in this study were FVPTC, which is known to be challenging due to the vague nuclear features in cytology specimens that frequently fall short of a definitive diagnosis of PTC and may lead to indeterminate FNA diagnoses. This is also supported by the fact that in the AUS/FLUS cases attributed to focal cytological atypia, the malignancy rate was $50 \%$ on follow-up; however, the malignancy rate in those attributed to compromised specimens or architectural atypia was dramatically less (approx. 20\%) and most of these malignancies were FVPTC. The reluctance to diagnose malignancy in a young patient may also explain the higher percentage of cases with indeterminate diagnoses, as a cautious approach is frequently used in pediatric cases. Furthermore, the higher AUS/FLUS rate may, in part, be due to the presence of compromised cases with low cellularity, which comprised approximately half of our AUS/FLUS cases, and may reflect the difficulty in sampling these lesions.

In adults, AUS/FLUS diagnoses with features concerning PTC have an increased risk of malignancy $[11,17,18]$. This is supported by the finding that subclassification of AUS/FLUS cases with qualifiers to indicate those without compromising features and focal cytological atypia, versus other subclassifications, demonstrated a higher risk of malignancy (38 vs. 7\%) [11]. A follow-up study with modified AUS/FLUS subclassification categories by patterns [(1) atypical, papillary carcinoma cannot be ruled out, (2) atypical, Hürthle cell neoplasm cannot be ruled out, (3) cellular atrophic pattern, (4) scant atrophic pattern, and (5) cytologic atypia alone] showed that AUS/ FLUS cases may be subclassified and this may help further stratify risk since cases of cytologic atypia demonstrated a higher risk of malignancy [17]. Another study focusing on adult thyroid nodules found that the risk of malignancy in AUS/FLUS cases with cytological atypia was approximately double that seen with architectural atypia (29 vs. 16\%) [18]. In our study of pediatric patients, we subclassified AUS/FLUS cases with broad qualifiers (compromised specimen, cytological atypia, and architectural atypia). This stratification showed a higher risk of malignancy in cases with cytologic atypia (50\%) and a 
lower risk of malignancy in compromised specimens (17\%). AUS/FLUS cases of focal architectural atypia had an intermediate risk of $20 \%$. In our prior study, the nondiagnostic pediatric thyroid FNAs had follow-up in $38 \%$ of cases and none were malignant, opposed to the compromised AUS/FLUS cases, which have a higher rate of malignancy (17\%) [13].

These findings suggest that the pediatric population may also benefit from further subclassification of AUS/ FLUS, as described in adults, but future studies are needed to validate subclassification of AUS/FLUS with cytologic atypia or concern for PTC that does not overlap significantly enough with the SM category. It also raises the possibility that patients may benefit from varying followup therapy based on such subclassification. For instance, pediatric patients with AUS/FLUS showing focal cytological atypia may benefit from surgery opposed to repeat FNA given the high rate of malignancy in this study. This is particularly important in children given that most thyroid FNAs in children at our institution are performed under general anesthesia and, thus, avoidance of a repeat FNA in this subset would avoid a repeat biopsy under anesthesia, and expedite treatment. Furthermore, molecular studies may also help stratify the AUS/FLUS cases in children, as shown in a previous paper from our institution [13], where 8 of these indeterminate pediatric thyroid FNAs (2 AUS/FLUS, 5 SFON, and 1 SM) had a mutation detected and subsequent malignancy in all cases. Thus, AUS/FLUS diagnoses in children may benefit from subcategorization or qualifiers, in addition to clinical, radiological, and molecular correlation, to select the most appropriate treatment.
Our study also noted a correlation with nodule size, as reported in other publications [19-23]. In general, the malignancies diagnosed as AUS/FLUS on preoperative FNA were smaller than the nodules diagnosed as malignant in the SFON or SM categories. When thyroid lesions were classified into two categories (benign and malignant lesions) and both categories contained lesions ranging from 0.7 to greater than $3 \mathrm{~cm}$ [19], the sensitivity of FNA was higher in larger nodules [20]. Other studies have shown that smaller nodules (measuring less than $3 \mathrm{~cm}$ ) have a greater percentage of insufficient or indeterminate cytological diagnoses [22] and a higher false-negative rate for nodules measuring less than $1 \mathrm{~cm} \mathrm{[23].} \mathrm{The} \mathrm{higher}$ rates of AUS/FLUS diagnoses in smaller lesions may represent sampling issues with limited cellular findings in samples where less material is available for easy aspiration, samples that may be diluted with normal surrounding thyroid material, or may be attributed to a cytopathologists' reluctance to commit to a diagnosis in a smaller lesion, particularly in children.

Overall, applying the TBSRTC to a pediatric population with thyroid nodules is an effective means of stratifying nodules, particularly in the spectrum of indeterminate diagnoses, and the categories correlate with an incremental risk of malignancy. In addition, the AUS/FLUS category continues to demonstrate the need for further diagnostic refinement as young patients may benefit from further cytological subclassification of these lesions, in addition to correlation with nodule size, and clinical and radiological findings, in order to select the most appropriate management.

\section{References}

1 Scott MD, Crawford JD: Solitary thyroid nodules in childhood: is the incidence of thyroid carcinoma declining? Pediatrics 1976;58: 521-525.

-2 Belfiore A, Giuffrida D, La Rosa GL, et al: High frequency of cancer in cold thyroid nodules occurring at young age. Acta Endocrinol (Copenh) 1989;121:197-202.

3 Niedziela M: Pathogenesis, diagnosis and management of thyroid nodules in children. Endocr Relat Cancer 2006;13:427-453.

$\checkmark 4$ Baloch ZW, LiVolsi VA, Asa SL, et al: Diagnostic terminology and morphologic criteria for cytologic diagnosis of thyroid lesions: a synopsis of the National Cancer Institute Thyroid Fine-Needle Aspiration State of the Science Conference. Diagn Cytopathol 2008; 36:425-437.
5 Cibas ES, Ali SZ: The Bethesda System for Reporting Thyroid Cytopathology. Thyroid 2009;19:1159-1165.

-6 Nikiforov YE, Ohori NP, Hodak SP, et al: Impact of mutational testing on the diagnosis and management of patients with cytologically indeterminate thyroid nodules: a prospective analysis of 1056 FNA samples. J Clin Endocrinol Metab 2011;96:3390-3397.

7 Nikiforov YE, Steward DL, Robinson-Smith $\mathrm{TM}$, et al: Molecular testing for mutations in improving the fine-needle aspiration diagnosis of thyroid nodules. J Clin Endocrinol Metab 2009;94:2092-2098.

8 Bongiovanni M, Krane JF, Cibas ES, Faquin WC: The atypical thyroid fine-needle aspiration: past, present, and future. Cancer Cytopathol 2012;120:73-86.
Faquin WC, Baloch ZW: Fine-needle aspiration of follicular patterned lesions of the thyroid: diagnosis, management, and follow-up according to National Cancer Institute (NCI) recommendations. Diagn Cytopathol 2010; 38:731-739.

10 Nayar R, Ivanovic M: The indeterminate thyroid fine-needle aspiration: experience from an academic center using terminology similar to that proposed in the 2007 National Cancer Institute Thyroid Fine Needle Aspiration State of the Science Conference. Cancer 2009; 117:195-202.

11 Renshaw AA: Should 'atypical follicular cells' in thyroid fine-needle aspirates be subclassified? Cancer Cytopathol 2010;118:186-189. 
12 Vanderlaan PA, Krane JF, Cibas ES: The frequency of 'atypia of undetermined significance' interpretations for thyroid fine-needle aspirations is negatively correlated with histologically proven malignant outcomes. Acta Cytol 2011;55:512-517.

13 Monaco SE, Pantanowitz L, Khalbuss WE, et al: Cytomorphological and molecular genetic findings in pediatric thyroid fine-needle aspiration. Cancer Cytopathol 2012;120:342-350.

14 Canadian Pediatric Thyroid Nodule (CaPTN) Study Group: The Canadian Pediatric Thyroid Nodule Study: an evaluation of current management practices. J Pediatr Surg 2008; 43:826-830.

15 Hosler GA, Clark I, Zakowski MF, Westra WH, Ali SZ: Cytopathologic analysis of thyroid lesions in the pediatric population. Diagn Cytopathol 2006;34:101-105.
16 Ohori NP, Nikiforova MN, Schoedel KE, LeBeau SO, Hodak SP, Seethala RR, Carty SE, Ogilvie JB, Yip L, Nikiforov YE: Contribution of molecular testing to thyroid fine-needle aspiration cytology of 'follicular lesion of undetermined significance/atypia of undetermined significance'. Cancer Cytopathol 2010; 118:17-23.

17 Renshaw AA: Subclassification of atypical cells of undetermined significance in direct smears of fine-needle aspirations of the thyroid: distinct patterns and associated risk of malignancy. Cancer Cytopathol 2011;119: 322-327.

18 VanderLaan PA, Marqusee E, Krane JF: Usefulness of diagnostic qualifiers for thyroid fine-needle aspirations with atypia of undetermined significance. Am J Clin Pathol 2011; 136:572-577.

19 Corrias A, Einaudi S, Chiorboli E, et al: Accuracy of fine needle aspiration biopsy of thyroid nodules in detecting malignancy in childhood: comparison with conventional clinical, laboratory, and imaging approaches. J Clin Endocrinol Metab 2001;86:4644-4648.
20 Redlich A, Boxberger N, Kurt Werner S, Fruhwald M, Rohrer T, Vorwerk P: Sensitivity of fine-needle biopsy in detecting pediatric differentiated thyroid carcinoma. Pediatr Blood Cancer 2012;59:233-237.

21 McCoy KL, Jabbour N, Ogilvie JB, Ohori NP, Carty SE, Yim JH: The incidence of cancer and rate of false-negative cytology in thyroid nodules greater than or equal to $4 \mathrm{~cm}$ in size. Surgery 2007;142:837-844.

22 Mehanna R, Murphy M, McCarthy J, O’Leary G, Tuthill A, Murphy MS, Sheahan P: False negatives in thyroid cytology: impact of large nodule size and follicular variant of papillary carcinoma. Laryngoscope 2013, DOI 10.1002/ lary.23861.

23 Shrestha M, Crothers BA, Burch HB: The impact of thyroid nodule size on the risk of malignancy and accuracy of fine-needle aspiration: a 10-year study from a single institution. Thyroid 2012;22:1251-1256. 